\title{
Nutritional stretegies to prevent Urolithiasis in Animals
}

\author{
Lipismita samal*, Ashok Kumar Pattanaik, Chinmoy Mishra, Biswa Ranjan Maharana, Laxmi \\ Narayan Sarangi and Rubina Kumari Baithalu \\ Indian Veterinary Research Institute \\ Izatnagar - 243122 (UP) India \\ * Corresponding author email: lipismitasamal@gmail.com
}

\begin{abstract}
Urolithiasis is a common problem in both ruminants and non-ruminants and nutrition plays a significant role in predisposing urolithiasis. The nutritional factors mainly influence urinary constituents and $\mathrm{pH}$, which affect stone nucleation and growth. While surgery can render a patient stone-free, non-operative treatment modalities are required to prevent and reduce the risk of recurrent urolithiasis. Moreover, long-term pharmacological therapy and its potential side effects often lead to subsequent failure. In this regard, nutritional management is the best preventive strategy against urolithiasis.
\end{abstract}

Keyw ords: Urolithiasis, Incidence, Herbal feed additives, Antioxidant therapy, Nutritional management.

\section{I ntroduction}

Urinary system is designed to dispose of body wastes in liquid form and the normal urine is in a state of meta-stable over-saturation (i.e. no spontaneous precipitation). The urine is a complex solution that allows mineral salts to be kept dissolved under oversaturation conditions. The urolithiasis presents a state of unstable over-saturation where a spontaneous precipitation exists and minerals precipitate, the crystals do not dissolve and they add together allowing the growth of the urolith (also called 'urinary stones' or 'calculi').

It is a condition of the urinary tract in which insoluble mineral and salt concretions develop and aggregate around a nidus of proteinaceous material mainly within the bladder or urethra (Belknap and Pugh, 2002) but it can occur anywhere in the urinary tract. Abnormal microscopic precipitates in urine are known as crystalluria whereas macroscopic concretions are called uroliths.

\section{Types of Stone}

There are mainly 5 types of stones - struvite, calcium oxalate, calcium phosphate, calcium carbonate and silica. Uric acid, cystine, hippuric acid, and tyrosine crystals may also be found. The presence of a specific type of crystal depends on the diet and transitory physical and chemical conditions that exist in the urine at that time.

\section{Incidence}

1) Species - Goats are most commonly affected followed by cattle, cats and dogs.

2) Age - In ruminants, young animals below 6 months of age are more affected because of high protein diet. Canines of middle age group (3-7yrs) have the highest incidence of urolithiasis.

3) Sex - Urolithiasis is not generally found in females due to flexible lumen of urethra.

4) Urinary $\mathrm{pH}$ - Acid $\mathrm{pH}$ of urine leads to precipitation of uric acid and cystine uroliths. Similarly, alkaline $\mathrm{pH}$ of urine leads to precipitation of struvite, calcium carbonate and calcium phosphate uroliths. However, solubility of silicates and oxalate uroliths don't depend on urinary $\mathrm{pH}$.

5) Castration status - Castrated animals are more susceptible than un-castrated ones.

6) Season - There is highest incidence of urolithiasis in ruminants during months of extreme winter (December-February) and extreme summer (March-June). However, the trend is reverse in canines where least number of cases is recorded during months of January and February.

7) Dietary habit - Obesity and associated dietary pattern increases urolithiasis (Siener, 2006).

\section{Treatment}

Surgical intervention is the primary step to release the pressure from bladder, which is further treated by medicinal means to establish the animal towards normalcy.

Limitation of Surgical Treatment: Various limitations of surgical therapy are difficulty in detection of urolithiasis at early stage, costly, quite 
common recurrence, careful follow up for a number of years, risks to long term fertility, potential side effects and no guarantee (Van Metre and Fubini, 2006).

\section{Prevenetive measures in Ruminants}

\section{General Preventive Strategies}

1. Optimize use of high quality forage - Ruminants need a minimum of $1.5 \%$ of their body weight as forage to ensure a healthy rumen (Schoenian, 2006);

2. Strategic use of concentrate feeds;

3. Optimum level of $\mathrm{Ca}: \mathrm{P}(1: 1$ to $2: 1)$ to avoid precipitation of excess phosphorus in the urine;

4. Ad libitum feeding to avoid marked changes in urine concentration;

5. Free choice of water; [The susceptibility of calves to urolithiasis increases when the water intake per unit forage DM intake declined below 3.5.]

6. Supplemental feeding of $\mathrm{NaCl} @ 3.5 \%$ of daily DM intake to promote greater water intake;

7. Strategic supplementation of calculogenic feeds like cottonseed meal, sorghum, Bengal gram, cotton seed meal, clovers, triticale and oxalate containing plants and feed supplements like stilbestrol, diethylstilbestrol, lime stone and sugarcane bagasse.

8. Grazing management practices like

a) Allowing only females to graze the risky pastures;

b) Permitting limited access of wethers and steers to oxalate rich pasture;

\section{Specific Preventive Strategies}

1) Calcic uroliths (Calcium oxalate and Calcium carbonate):

* Low calcium, Low oxalate and High moisture

* Restrict animal protein, vitamin $\mathrm{C}$ and $\mathrm{NaCl}$, Do not restrict phosphorus and magnesium

* Supplement Vitamin B6 and potassium citrate (100$150 \mathrm{mg} / \mathrm{kg} /$ day) to prevent recurrent Ca-oxalate stones * Low arachidonic acid (Naya et al., 2002)

* Low feeding of pelleted alfalfa to decrease the incidence of calcium carbonate stones

* Higher dose of citrate inhibits calcium absorption; phytic acid and/or zinc may also be useful for treatment

2) Phosphatic uroliths (Struvite, Calcium phosphate) Maintenance of a total ration Ca: $\mathrm{P}$ of 2:1 and a dietary $\mathrm{Mg}$ level at $0.2-0.3 \%$ (DM basis) will prevent phosphatic urolithiasis. Majority of ammonium and phosphate in urine comes from protein in diet. So, low protein diet should be fed. The uroliths can be dissolved effectively by various acidifiers like $4 \% \mathrm{NaCl}, 10 \%$ acetic acid, D, Lmethionine, ascorbic acid, $0.5-1 \% \mathrm{NH} 4 \mathrm{Cl}$ ( or $45 \mathrm{~g} /$ day to steers and $10 \mathrm{~g} /$ day to sheep) and phosphoric acid.

3) Siliceous uroliths

* Supplements containing 3-5\% NaCl or $1-2 \% \mathrm{NH} 4 \mathrm{Cl}$

* Phosphorus supplementation

* Avoid high plant proteins (e.g. soybean hulls, corn gluten)

* Water intake $>200 \mathrm{~g} / \mathrm{kg}$ b.w./day

4) Cystine uroliths: Potassium citrate, sodium bicarbonate, $\mathrm{CaCO} 3$ and lactate can be used.

\section{Preventive measures in Pets}

In dogs and cats, struvite urolithasis is most common followed by urate, cystine, and calcium oxalate.

\section{General Preventive Strategies}

1. Low level of high quality protein to reduce excretion of urea;

2. Low calcium, phosphorus and magnesium to reduce concentration of calculi constituents;

3. High sodium to induce a large volume of low concentration urine;

4. Typical diet for treatment of urolithiasis in dog should contain $8 \%$ protein, $0.3 \%$ calcium, $0.12 \%$ phosphorus, $0.02 \%$ magnesium and $1.2 \%$ sodium in the DM, 1-2 mg/kg/day K, 1-2 mg/kg/day Zn and 100$200 \mathrm{mg} / \mathrm{d}$ Vit. B12.

\section{Specific Preventive Strategies}

1) Struvite uroliths: Diets should have a low content of magnesium and phosphorus. Urine $\mathrm{pH}$ should be lowered and output increased by feeding low protein, high sodium diet. Water consumption of pets can be increased by switching pets from dry food ( $<12 \%$ water) to wet food ( $75 \%$ water). When feeding of wet food is not practical, dry food is supplemented with urinary acidifiers like $\mathrm{NH} 4 \mathrm{Cl}$ salt $(0.5-1 \%$ of $\mathrm{DMI}$ ) or $1-2 \mathrm{~g} \mathrm{D}, \mathrm{L}-$ methionine. $\mathrm{NH} 4 \mathrm{Cl}$ is unpalatable. So, table sugar can be added in diet. Molasses should be avoided as flavoring additive because its high potassium content may diminish the acidifying effect of $\mathrm{NH} 4 \mathrm{Cl}$.

2) Urate uroliths: It is treated by feeding diets containing around $10 \%$ protein and $70 \%$ moisture in dogs.

3) Cystine uroliths: It is treated by feeding low protein and low sodium diets. Commercial calculolytic diets for all types of uroliths are prescribed by Hill's Pet Nutrition, U.K. (Meyer, 2004) and Waltham Centre for Pet Nutrition, U.K. (Kirk et al., 2001).

\section{Recent Advances in Nutritional Research on Urolithiasis}

Herbal Feed Additives: For calcium oxalate uroliths, Crataeva nurvala, Costus spiralis, Coleus 
aromaticus, Moringa olifera Lam., Raphanus sativus, Musa paradisiaca, Homonia riparia, Petroselinum sativum, Ammania baccifera and Trigonella foenumgraceum are effective. For calcium phosphate uroliths, Bergenia ligulata, M. paradisiaca, Tribulus terrestris, Dolichos biflorus and A. baccifera; and for struvite uroliths, $H$. riparia and $A$. baccifera are effective (Prasad et al., 2007). The marketed herbal formulations are Cystone (Himalaya Drug Company, India), Calculi (Charak Pharmaceuticals, India), Chandraprabha bati (Baidyanath, India) and Trinapanchamool.

\section{Antioxidant therapy}

Oxalate induces free radical generation, which results in per-oxidative injury to renal epithelial cells (Thamilselvan et al., 2005). So, vitamins like Vit-E, Vit-A and Vit-C act as chain breaking antioxidants. They intercept free radical induced chain reaction and prevent further oxidation thus possess potential to be used as anti-stone forming nutrients (Kato et al., 2007). Role of free radical scavenger for prevention of ca-oxalate urolith in kidney was studied in rats. Both superoxide and $\mathrm{H}_{2} \mathrm{O}_{2}$ generating enzymes like glycolic acid oxidase and xanthine oxidase were increased in hyperoxaluric rats. Antioxidant therapy with vitamin E, selenium, methionine, lipoic acid, fish oil, phytic acid, ascorbic acid, potassium citrate, sodium citrate, magnesium oxide, phycocyanin and mannitol normalized the cellular oxidation system by decreasing the levels of lipid peroxidases and the activities of oxalate synthesizing enzymes like glycolic acid oxidases, lactate dehydrogenase, xanthine oxidase and increasing the activities of enzymatic antioxidants like superoxide desmutase and catalase thus preventing $\mathrm{Ca}$-oxalate uroliths.

\section{Ongoing Research Projects}

1) Minnesota Urolith Centre, USA: Urolithiasis in pet animals.

2) University of Balaeric Islands, Spain: Antiurolithiatic activities of Zea mays, Rosa canina, Herniaria hirsute and potential of phytates in calcium uroliths.

3) University of California, Davis: Urolithiasis in pigmy goats.

4) Central Drug Research Institute, India.

5) Tianjin Institute of Pharmaceutical Research,
China: Efficacy of Brown algae extract (Zhao, et.al., 2007).

6) Clinical Research Institute, Seoul, Korea: Potential of Lactobacillus culture (Lactobacillus casei HY-2743 and L. casei HY-7201) (Kwak et al., 2006).

\section{Conclusion}

Nutritional management is the best preventive strategy against urolithiasis. As such it may not replace the surgical procedures but may surely help in decreasing the recurrence rate of uroliths. The future research should target on experimental validation of metabolic effects of dietary changes on urolithiasis in target animals and research on antioxidants and herbal plants for their anti-urolithiatic role.

\section{References}

1. Belknap, E.B. and Pugh, D.G. (2002). Diseases of the urinary system. W.B. Saunders Company, Philadelphia, USA

2. Kato, J., Ruram, A.A., Singh, S., Devi, S.B., Devi, T. and Singh, W.G. (2007). Lipid peroxidation and antioxidant vitamins in urolithiasis. Ind. J. of Cli. Biochem., 22(1): 128130.

3. Kirk, C.A., Lund, E., Armstrong, P. (2001). Prevalence of lower urinary tract disorders of dogs and cats in the United States. Proceedings of Waltham International Symposium, pp. 61.

4. Kwak, C., et.al. (2006). Prevention of nephrolithiasis by Lactobacillus in stone-forming rats: a preliminary study. Urol. Research, 34(4): 265-270.

5. Meyer, H.P. (2004). The diagnosis and treatment of chronic renal failure in the dog and cat. Scientific Proceedings of WSAVA-FECAVA-HVMS World Congress, pp. 522-528.

6. Naya, Y., Ito, H., Masai, M. and Yamaguchi, K.(2002) Association of dietary fatty acids with urinary oxalate excretion in calcium oxalate stone-formers in their fourth decade. B.J.U.Int., 89(9): 842-846.

7. Prasad, K.V.S.R.G., Sujatha, D., Bharathi, K. (2007). Herbal drugs in urolithiasis- A review. Pharmacognosy Reviews, 1(1): $175-179$.

8. Schoenian, S. (2006). The truth about grain: Feeding grain to small ruminants. Western Maryland Research and Education Centre; Maryland Cooperative Extension.

9. Siener, R. (2006). Impact of dietary habits on stone incidence. Urol. Research, 34(2): 131-133.

10. Thamilselvan, S., Menon, M. (2005).Vitamin E therapy prevents hyperoxaluria-induced calcium oxalate crystal deposition in the kidney by improving renal tissue antioxidant status. B.J.U. Int., 96: 117-126.

11. Van Metre, D. and Fubini, S.L. (2006). Ovine and caprine urolithiasis: Another piece of the puzzle. Vet. Surgery, 35: 413-416. 